\title{
Preventive Effect of Alkaloids from Lotus plumule on Acute Liver Injury in Mice
}

\author{
Bihui Liu ${ }^{1,2,3,4,+}, \mathrm{Ji} \mathrm{Li}^{4,+}$, Ruokun Yi ${ }^{1,2,3}$, Jianfei Mu ${ }^{1}$, Xianrong Zhou ${ }^{1}$ and Xin Zhao ${ }^{1,2,3, * \mathbb{D}}$ \\ 1 Chongqing Collaborative Innovation Center for Functional Food, Chongqing University of Education, \\ Chongqing 400067, China; liubh@foods.ac.cn (B.L.); yirk@cque.edu.cn (R.Y.); mujianfei@foods.ac.cn (J.M.); \\ zhouxr@foods.ac.cn (X.Z.) \\ 2 Chongqing Engineering Research Center of Functional Food, Chongqing University of Education, \\ Chongqing 400067, China \\ 3 Chongqing Engineering Laboratory for Research and Development of Functional Food, \\ Chongqing University of Education, Chongqing 400067, China \\ 4 College of Biological and Chemical Engineering, Chongqing University of Education, Chongqing 400067, \\ China; liji@foods.ac.cn \\ * Correspondence: zhaoxin@cque.edu.cn; Tel.: +86-23-6265-3650 \\ + These authors contributed equally to this work.
}

Received: 19 December 2018; Accepted: 16 January 2019; Published: 19 January 2019

\begin{abstract}
Lotus plumule is a traditional Chinese food that can be used as a beverage. In this study, three kinds of Lotus plumules from different regions of China were selected to observe the preventive effects of extracted alkaloids on $\mathrm{CCl}_{4}$-induced liver injuries. Animal experiments revealed that alkaloids extracted from Lotus plumules decreased the serum AST (aspartate aminotransferase), ALT (alanine aminotransferase), and TBIL (total bilirubin) levels, enhanced SOD (superoxide dismutase) activity, and reduced MDA (malondialdehyde) level in the liver tissues of mice with liver injury. $\mathrm{H} \& \mathrm{E}$ observation confirmed that alkaloids from Lotus plumules could alleviate $\mathrm{CCl}_{4}$-induced injuries of liver tissues and inhibit the inflammatory effect on hepatocytes. Further qPCR experiments also demonstrated that alkaloids from Lotus plumules upregulated the expression of IкB- $\alpha$ (inhibitor of NF-KB alpha), $\mathrm{Cu} / \mathrm{Zn}$-SOD (copper/zinc superoxide dismutase), Mn-SOD (manganese superoxide dismutase), and CAT (catalase) mRNA and downregulated TNF- $\alpha$ (tumor necrosis factor alpha) and NF-KB (nuclear factor kappa B) expression in the liver tissues of mice with liver injury. All three kinds of alkaloids from Lotus plumules could prevent $\mathrm{CCl}_{4}$-induced liver injuries by regulating the levels of oxidative stress and inflammation in mice, and the therapeutic effect was comparable to that of silymarin, the medicine commonly used in the treatment of liver diseases. In summary, alkaloids from Lotus plumules contain bioactive substances with hepatic protective efficacy and possess potential application value in the field of functional food.
\end{abstract}

Keywords: Lotus plumule; antioxidant; liver injury; gene; mice

\section{Introduction}

Lotus plumule is the green radicle in the middle of mature seeds of Nymphaeaceae plant lotus. In addition to being a traditional Chinese medicine, it is more commonly used as a beverage in China [1]. Lotus plumule is rich in alkaloids and sterols, and it also contains water-soluble polysaccharides and a variety of micronutrients [2]. In traditional Chinese medicine, Lotus plumule has the effects, such as nourishing Yin, suppressing hyperactive yang, purging fire, eliminating toxins, clearing heat, cooling the blood, promoting the secretion of saliva and body fluid, regulating Qi, protecting the stomach and the liver, improving vision, and inducing ataraxia [3]. Modern medical science also proves that Lotus plumule can lower blood pressure by regulating blood vessels and smooth muscles [4]. Studies 
have also shown that Lotus plumule has a good effect of clearing oxygen free radicals. It can capture lipid peroxide free radicals generated in the process of oxidation, stimulate the enzymatic antioxidant mechanisms, activate and enhance the activities of antioxidant enzymes, such as SOD (superoxide dismutase) and CAT (catalase), and block the oxidative chain reaction of free radicals, thereby rapidly clearing free radicals in living organisms [5].

The liver is the largest solid organ in the abdominal cavity and plays an important physiological role in the human body. Hepatic arteries and portal veins provide abundant blood supply, since hepatocytes are vulnerable to hypoxia, and bile ducts accompanying blood vessels transport bile. However, the liver is easily damaged due to its large size and fragility and causes intra-abdominal hemorrhage or bile leakage, resulting in hemorrhagic shock or biliary peritonitis that has serious consequences [6]. The oxidative stress induced by reactive oxygen species is the common pathophysiological basis of many hepatic diseases. Oxidative stress mainly changes the function of biofilm, covalently binds to biomacromolecules, and hampers the activity of enzymes by initiating membrane lipid peroxidation, which in combination with cytokines, such as TNF- $\alpha$ and NF- $\mathrm{kB}$, results in various degrees of liver injury. Oxidative stress plays an important role in the progress of fatty liver, viral hepatitis, and liver fibrosis $[7,8] . \mathrm{CCl}_{4}$ is a common inducer of liver injuries. A large number of harmful free radicals will be generated by the activation of liver microsomal cytochrome P-450 after $\mathrm{CCl}_{4}$ enters the body, which increases calcium ion influx by reducing the activity of calcium pump in the endoplasmic reticulum, promotes the production of inflammatory cytokines in hepatocytes, aggravates inflammation, induces the activation of phosphorylase on the membrane of hepatocytes, causes membrane peroxidation, destroys hepatocyte membrane, and leads to liver injuries [9].

Alkaloids are a class of alkaline organic compounds containing nitrogen in the plants. Plant alkaloids, such as Coptidis alkaloids, alkaloids in Caulis mahoniae, and Clivia miniata alkaloids all show strong antioxidant effects. These plant alkaloids have bacteriostatic activities and protective effects on liver and kidney functions [10-12]. Studies have also shown that alkaloids from Lotus plumule have various health care functions, such as anti-hypertension, anti-oxidation and protection of the myocardium [13].

In this study, to determine the effect of Lotus plumule alkaloids, three Lotus plumules from China's main Lotus plumule producing areas were selected, the vast majority of Lotus plumule varieties in China come from the three Lotus plumules selected in this study, so we chose these three representative lotus seed hearts for the observation of preventive effect of Lotus plumule alkaloids on acute liver injuries in mice. An acute liver injury model was established with carbon tetrachloride. The preventive effect on liver injury was verified by examining biochemical indices and mRNA expressions. Results of this study will provide the theoretical basis for the further precision application of alkaloids from Lotus plumule, which will contribute to the development and application of these agents.

\section{Materials and Methods}

\subsection{Extraction of Alkaloids from Lotus Plumule}

Ultrasound-assisted extraction with higher extracting activity was used. The Lotus plumules were pulverized after drying at $90{ }^{\circ} \mathrm{C}$ for $2 \mathrm{~h}$. $100 \mathrm{~g}$ of Lotus plumule powder was accurately weighed and placed in a plugged conical flask. $500 \mathrm{~mL} 65 \%$ ethanol was added, and the sealed conical flask was fixed in an ultrasonic cleaner. Extraction was carried out by $220 \mathrm{~W}$ ultrasound at $30^{\circ} \mathrm{C}$ for $45 \mathrm{~min}$, and then extracted liquid was filtered. The residue was mixed with $500 \mathrm{~mL} 65 \%$ ethanol and extracted by ultrasound once more under the same conditions. Extracted liquids were collected and filtered by a Brinell funnel. The filtrate was concentrated and dissolved in the appropriate amount of water. A hydrochloric acid solution was used to adjust the $\mathrm{pH}$ level to 1-2. After filtration, extracted liquids were adjusted to $\mathrm{pH} 9-10$ with ammonia solution. After standing, extracted liquids were centrifuged at $3000 \mathrm{r} / \mathrm{min}$ for $10 \mathrm{~min}$ and alkaloids from Lotus plumule were obtained after drying at $50{ }^{\circ} \mathrm{C}$ [14]. 


\subsection{Determination of Alkaloid Content}

Standard neferine was used as a reference substance for determining the content of alkaloids extracted from Lotus plumules. The standard neferine was weighed and dissolved in $0.1 \mathrm{~mol} / \mathrm{L}$ hydrochloric acid solution to prepare neferine solution at the mass concentrations of 15, 20, 25, 30, 35, 40,45 and $50 \mu \mathrm{g} / \mathrm{mL}$. The absorbance (A) of the above solutions was measured at the wavelength of $276 \mathrm{~nm}$. The standard curve was obtained with A serving as the ordinate versus mass concentration of neferine (@) as the abscissa [15].

\subsection{Animal Experiments with Mice}

Sixty 6-week-old male SPF KM mice (Chongqing Medical University, Chongqing, China) were kept for adaptation to the environment for $1 \mathrm{w}$ and were divided into six groups: Normal group, control group, silymarin group and groups of total alkaloids of lotus seeds from Hunan Province (LSA-HN), Jiangxi Province (LSA-JX), and Hubei Province (LSA-JX), with 10 mice in each group. Mice in the normal and control groups were gavaged with normal saline. Mice in the silymarin group were gavaged with $200 \mathrm{mg} / \mathrm{kg}$ silymarin (Sigma-Aldrich, Inc., St. Louis, MO, USA), while mice in the LSA-HN, LSA-JX and LSA-HB groups were gavaged with LSA-HN, LSA-JX and LSA-HB at the concentration of $400 \mathrm{mg} / \mathrm{kg}$, respectively. The above administrations lasted $10 \mathrm{~d}$. At Day 10, mice in the control, silymarin, and alkaloid groups were intraperitoneally injected with vegetable oil- $\mathrm{CCl}_{4}$ solution $\left(0.8 \% \mathrm{CCl}_{4}\right.$ solution, injection dose of $\left.0.1 \mathrm{~mL} / 10 \mathrm{~g}\right) 1 \mathrm{~h}$ after gavage, whereas mice in the normal group were intraperitoneally injected with the same dose of vegetable oil alone [16]. After intraperitoneal injection of $\mathrm{CCl}_{4}$ solution, all experimental mice were fasted for $24 \mathrm{~h}$ and the liver tissue and blood of mice were collected for further experiments after sacrifice. The liver tissue index of mice was determined as organ mass $(\mathrm{g}) /$ body mass $(\mathrm{kg}) \times 100$. This study was conducted in accordance with the Declaration of Helsinki, and the protocol was approved by the Ethics Committee of Chongqing Collaborative Innovation Center for Functional Food (201802001B).

\subsection{Detection of Serum AST, ALT and TBIL Levels}

The obtained plasma was centrifuged at $4000 \mathrm{rpm}$ for $10 \mathrm{~min}$, and the upper serum was collected. Then the levels of aspartate transaminase (AST), alanine transaminase (ALT), and total bilirubin (TBIL) in the serum of mice were measured by the kits (Nanjing Jiancheng Bioengineering Institute, Nanjing, China).

\subsection{Detection of SOD and MDA Levels in Liver Tissues}

The $10 \%$ homogenate was obtained from the liver tissue of the mice and centrifuged at $4000 \mathrm{rpm}$ for $10 \mathrm{~min}$. The supernatant was collected and the levels of superoxide dismutase (SOD) and malondialdehyde (MDA) in the liver tissue were measured by the kits (Nanjing Jiancheng Bioengineering Institute, Nanjing, China).

\subsection{Pathological Observation of Liver Tissue}

About $0.5 \mathrm{~cm}^{2}$ of mice liver tissue was fixed in $10 \%$ formalin solution for $48 \mathrm{~h}$. The liver tissue was then dehydrated, cleared, waxed, embedded, sliced, and stained with $\mathrm{H} \& \mathrm{E}$ stain. The morphological changes in the liver tissues were observed under an optical microscope (BX43, Olympus, Tokyo, Japan).

\subsection{Quantitative PCR ( $q P C R)$ Assay}

The tongue tissues of the mice were pulverized. Total RNA (Thermo Fisher Scientific, Inc., Waltham, MA, USA) in the tongue tissues was extracted with RNAzol and the concentration of extracted total RNA was diluted to $1 \mu \mathrm{g} / \mu \mathrm{L}$. Then $5 \mu \mathrm{L}$ of diluted total RNA solution was collected and used for reverse transcription to obtain the cDNA template according to the kit instruction. $2 \mu \mathrm{L}$ cDNA template was mixed with $10 \mu \mathrm{L}$ SYBR Green PCR Master Mix and $1 \mu \mathrm{L}$ upstream and downstream 
primers (Table 1). The reaction was performed at $95^{\circ} \mathrm{C}$ for $60 \mathrm{~s}$, then 40 cycles at $95^{\circ} \mathrm{C}$ for $15 \mathrm{~s}, 55^{\circ} \mathrm{C}$ for $30 \mathrm{~s}$, and $72{ }^{\circ} \mathrm{C}$ for $35 \mathrm{~s}$. Finally, the detection was carried out under the conditions at $95^{\circ} \mathrm{C}$ for $30 \mathrm{~s}$ and $55^{\circ} \mathrm{C}$ for $35 \mathrm{~s}$. The relative expressions of genes were calculated by $2^{-\Delta \Delta \mathrm{Ct}}$ method with GAPDH serving as the internal reference [17].

Table 1. Sequences of primers used in this study.

\begin{tabular}{|c|c|}
\hline Gene Name & Sequence \\
\hline \multirow{2}{*}{ TNF- $\alpha$} & Forward: 5'-CGAGTGACAAGCCCGTAGCC-3' \\
\hline & Reverse: 5'-GGATGAACACGCCAGTCGCC-3' \\
\hline \multirow{2}{*}{ NF- $k B$} & Forward: 5'-ATGGCAGACGATGATCCCTAC-3' \\
\hline & Reverse: 5'-CGGAATCGAAATCCCCTCTGTT-3' \\
\hline \multirow{2}{*}{ IкB- $\alpha$} & Forward: 5'-ATGGCAGACGATGATCCCTAC-3' \\
\hline & Reverse: 5'-CGGAATCGAAATCCCCTCTGTT-3' \\
\hline \multirow{2}{*}{$\mathrm{Cu} / \mathrm{Zn}-\mathrm{SOD}$} & Forward: 5'-AACCAGTTGTGTTGTCAGGAC-3' \\
\hline & Reverse: 5'-CCACCATGTTTCTTAGAGTGAGG-3' \\
\hline \multirow{2}{*}{ Mn-SOD } & Forward: 5'-CAGACCTGCCTTACGACTATGG-3' \\
\hline & Reverse: 5'-CTCGGTGGCGTTGAGATTGTT-3' \\
\hline \multirow[b]{2}{*}{ CAT } & Forward: 5'-GGAGGCGGGAACCCAATAG-3' \\
\hline & Reverse: 5'-GTGTGCCATCTCGTCAGTGAA-3' \\
\hline \multirow{2}{*}{ GAPDH } & Forward: 5'-AGGTCGGTGTGAACGGATTTG-3' \\
\hline & Reverse: 5'-GGGGTCGTTGATGGCAACA-3' \\
\hline
\end{tabular}

TNF- $\alpha$, tumor necrosis factor $\alpha$; NF- $\mathrm{kB}$, nuclear factor $\mathrm{k}$-light-chain-enhancer of activated B cells; IkB- $\alpha$, nuclear factor of $\kappa$-light polypeptide gene enhancer in B-cells inhibitor- $\alpha ; \mathrm{Cu} / \mathrm{Zn}$-SOD, cuprozinc-superoxide dismutase; Mn-SOD, manganese superoxide dismutase; CAT, catalase; GAPDH, glyceraldehyde-3-phosphate dehydrogenase.

\subsection{Statistical Analysis}

Three parallel experiments were performed on the serum and tissue indices of each mouse, and the average values were obtained. Statistical software SAS9.1 (SAS Institute Inc., DriveCary, NC, USA) was used to analyze the data. One-way ANOVA according to Duncan's multiple-range test was used to judge whether there were significant differences among groups at the level of $p<0.05$. If the superscript letters of data using a to $d$ were the same, it meant that there was no significant difference between the data marked by the same letter at $p>0.05$ level; if the superscript letters of data using a to $\mathrm{d}$ were different, it means that there was a significant difference between the data marked by different letters at $p<0.05$ level.

\section{Results}

\subsection{Content of Alkaloids Extracted from Lotus Plumules}

Neferine served as the standard substance and the regression equation was $\mathrm{A}=59.849 \varrho+0.8694$ $\left(R^{2}=0.9988\right)$. According to the regression curve, the purity of alkaloid extracts in the LSA-HN, LSA-JX, and LSA-HB groups were similar (Table 2). It can be seen that the substances that played core biological roles in the further animal experiments were the components of alkaloids from Lotus plumules.

Table 2. Content of alkaloids extracted from Lotus plumules.

\begin{tabular}{ccc}
\hline LSA-HN & LSA-JX & LSA-HB \\
\hline $65.3 \% \pm 1.23^{\mathrm{a}}$ & $66.7 \pm 2.37^{\mathrm{a}}$ & $66.2 \pm 2.08^{\mathrm{a}}$ \\
\hline
\end{tabular}

a Mean values the date are not efficiently different $(p>0.05)$ by Duncan's multiple range test. SA-HN, alkaloids of Lotus plumule from Hunan, China; LSA-JX, alkaloids of Lotus plumule from Jiangxi, China; LSA-HB, alkaloids of Lotus plumule from Hubei, China.

\subsection{Body Weight, Liver Weight and Liver Index of Mice}

As shown in Table 3, except that the mice in the normal group had slightly higher body weight, body weights of mice in each group were similar, and there was no significant difference in the body 
weights in each group $(p>0.05)$. The liver weights of normal mice were lowest, while the liver weights of control mice were significantly higher than those in other groups $(p<0.05)$. The liver weights of mice with $\mathrm{CCl}_{4}$-induced liver injuries were decreased with the gavage of alkaloids from Lotus plumules. The results of the liver index are similar to those of liver weight. The control group had the highest liver index. The liver index of mice with $\mathrm{CCl}_{4}$-induced liver injuries was significantly lower than that of the control group $(p<0.05)$ after gavage with alkaloids from Lotus plumules.

Table 3. Effects of alkaloids from Lotus plumules on body weight, liver weight and liver index of mice with hepatic injury induced by carbon tetrachloride $(N=10)$.

\begin{tabular}{cccc}
\hline Group & Body Weight $(\mathrm{g})$ & Liver Weight $(\mathrm{g})$ & Liver Index $^{\mathrm{a}}$ \\
\hline Normal & $32.00 \pm 0.92^{\mathrm{a}}$ & $1.44 \pm 0.79^{\mathrm{c}}$ & $4.5 \pm 0.2^{\mathrm{c}}$ \\
Control & $29.28 \pm 1.57^{\mathrm{a}}$ & $1.89 \pm 0.96^{\mathrm{a}}$ & $6.5 \pm 0.5^{\mathrm{a}}$ \\
Silymarin & $29.45 \pm 1.53^{\mathrm{a}}$ & $1.70 \pm 0.68^{\mathrm{b}}$ & $5.8 \pm 0.4^{\mathrm{b}}$ \\
LSA-HN & $29.29 \pm 1.81^{\mathrm{a}}$ & $1.71 \pm 0.20^{\mathrm{b}}$ & $5.8 \pm 0.5^{\mathrm{b}}$ \\
LSA-JX & $30.01 \pm 1.30^{\mathrm{a}}$ & $1.82 \pm 0.15^{\mathrm{b}}$ & $6.1 \pm 0.4^{\mathrm{b}}$ \\
LSA-HB & $29.9 \pm 71.29^{\mathrm{a}}$ & $1.80 \pm 0.13^{\mathrm{b}}$ & $6.0 \pm 0.4^{\mathrm{b}}$ \\
\hline
\end{tabular}

Values presented are the mean \pm standard deviation $\left(N=10\right.$ /group). ${ }^{\text {a-c }}$ Mean values with different superscript letters are significantly different $(p<0.05)$ by the Duncan's multiple-range test. Silymarin, mice treated with $200 \mathrm{mg} / \mathrm{kg}$ silymarin; LSA-HN, mice treated with $400 \mathrm{mg} / \mathrm{kg}$ Lotus plumule alkaloids (Hunan, China); LSA-JX, mice treated with $400 \mathrm{mg} / \mathrm{kg}$ Lotus plumule alkaloids (Jiangxi, China); LSA-HB, mice treated with $400 \mathrm{mg} / \mathrm{kg}$ Lotus plumule alkaloids (Hubei, China).

\subsection{Serum Levels of AST, ALT and TBIL in Mice}

Mice in the normal group had the lowest serum levels of AST, ALT and TBIL (Table 4). The control group with $\mathrm{CCl}_{4}$-induced liver injury showed the opposite trend with the highest levels of AST, ALT, and TBIL. Compared with the control group, silymarin and alkaloid could significantly downregulate the levels of AST, ALT, and TBIL in mice with liver injuries $(p<0.05)$. There was no significant difference in serum indicators among the groups of Lotus plumule alkaloids from different regions $(p>0.05)$. The levels of AST, ALT, and TBIL in the silymarin group were lower than those in alkaloid groups from different regions, and were close to those in the normal group.

Table 4. The levels of AST, ALT and TBIL in the serum from the mice $(N=10)$.

\begin{tabular}{cccc}
\hline Group & AST (U/L) & ALT (U/L) & TBIL $(\mu \mathrm{mol} / \mathbf{L})$ \\
\hline Normal & $19.32 \pm 3.92^{\mathrm{c}}$ & $29.08 \pm 7.20^{\mathrm{d}}$ & $14.93 \pm 3.93^{\mathrm{c}}$ \\
Control & $75.50 \pm 4.32^{\mathrm{a}}$ & $218.55 \pm 21.28^{\mathrm{a}}$ & $40.31 \pm 0.82^{\mathrm{a}}$ \\
Silymarin & $41.92 \pm 1.21^{\mathrm{b}}$ & $141.41 \pm 13.92^{\mathrm{c}}$ & $16.27 \pm 2.41^{\mathrm{c}}$ \\
LSA-HN & $46.06 \pm 1.61^{\mathrm{b}}$ & $174.241 \pm 3.43^{\mathrm{b}}$ & $33.97 \pm 9.27^{\mathrm{b}}$ \\
LSA-JX & $53.56 \pm 7.70^{\mathrm{b}}$ & $169.43 \pm 12.59^{\mathrm{b}}$ & $21.61 \pm 2.18^{\mathrm{b}}$ \\
LSA-HB & $43.75 \pm 5.32^{\mathrm{b}}$ & $171.64 \pm 13.52^{\mathrm{b}}$ & $31.85 \pm 9.85^{\mathrm{b}}$ \\
\hline
\end{tabular}

Values presented are the mean \pm standard deviation $\left(N=10\right.$ /group). ${ }^{\text {a-d }}$ Mean values with different superscript letters are significantly different $(p<0.05)$ by the Duncan's multiple-range test. Silymarin, mice treated with $200 \mathrm{mg} / \mathrm{kg}$ silymarin; LSA-HN, mice treated with $400 \mathrm{mg} / \mathrm{kg}$ Lotus plumule alkaloids (Hunan, China); LSA-JX, mice treated with $400 \mathrm{mg} / \mathrm{kg}$ Lotus plumule alkaloids (Jiangxi, China); LSA-HB, mice treated with $400 \mathrm{mg} / \mathrm{kg}$ Lotus plumule alkaloids (Hubei, China).

\subsection{SOD and MDA Levels in Liver Tissues of Mice}

Mice in the normal group had the highest SOD activity level and lowest MDA activity level in the liver tissue (Table 5). The control group with $\mathrm{CCl}_{4}$-induced liver injury showed the opposite trend with the lowest SOD activity level and the highest MDA activity level. Compared with the control group, gavages of silymarin and Lotus plumule alkaloids from different regions significantly promoted the SOD activity and reduced the MDA activity in the injured liver tissues of mice $(p<0.05)$. The levels of SOD and MDA in the silymarin group were close to those in the normal group, and there was no significant difference among the groups of alkaloids from different regions $(p>0.05)$. 
Table 5. The levels of superoxide dismutase (SOD) and malondialdehyde (MDA) in hepatic tissue of mice $(N=10)$.

\begin{tabular}{ccc}
\hline Group & SOD (U/mg) & MDA (nmol/mg) \\
\hline Normal & $138.65 \pm 6.58^{\mathrm{a}}$ & $1.23 \pm 0.18^{\mathrm{d}}$ \\
Control & $52.71 \pm 3.07^{\mathrm{d}}$ & $2.69 \pm 0.24^{\mathrm{a}}$ \\
Silymarin & $108.87 \pm 5.38^{\mathrm{b}}$ & $1.66 \pm 0.19^{\mathrm{c}}$ \\
LSA-HN & $82.51 \pm 4.33^{\mathrm{c}}$ & $2.08 \pm 0.16^{\mathrm{b}}$ \\
LSA-JX & $83.06 \pm 5.51^{\mathrm{c}}$ & $1.99 \pm 0.17^{\mathrm{b}}$ \\
LSA-HB & $81.88 \pm 3.10^{\mathrm{c}}$ & $2.04 \pm 0.12^{\mathrm{b}}$ \\
\hline
\end{tabular}

Values presented are the mean \pm standard deviation (N=10/group). ${ }^{a-d}$ Mean values with different superscript letters are significantly different $(p<0.05)$ by the Duncan's multiple-range test. Silymarin, mice treated with $200 \mathrm{mg} / \mathrm{kg}$ silymarin; LSA-HN, mice treated with $400 \mathrm{mg} / \mathrm{kg}$ Lotus plumule alkaloids (Hunan, China); LSA-JX, mice treated with $400 \mathrm{mg} / \mathrm{kg}$ Lotus plumule alkaloids (Jiangxi, China); LSA-HB, mice treated with $400 \mathrm{mg} / \mathrm{kg}$ Lotus plumule alkaloids (Hubei, China).

\subsection{Pathological Observation of Mice Liver}

The histopathological sections of mouse liver tissues were observed under a microscope (Figure 1). The hepatic lobular structure of mice in the normal group was clear. The hepatocytes arranged radially around the end of the central vein. The proportion of the sinus was normal. The boundary of the hepatic cells was clear, and the nuclei were located in the center of cells. No hyperplasia of fibrous tissues could be found in the portal area. In the control group, the structure of hepatic tissues was disordered, and a wide range of steatosis, vacuolar degeneration, and diffuse necrosis of hepatocytes appeared. Compared with the control group, silymarin and alkaloids from Lotus plumules could alleviate the $\mathrm{CCl}_{4}$-induced injuries of liver tissues, reducing changes in the hepatic tissue structure and hepatocyte morphology in mice.

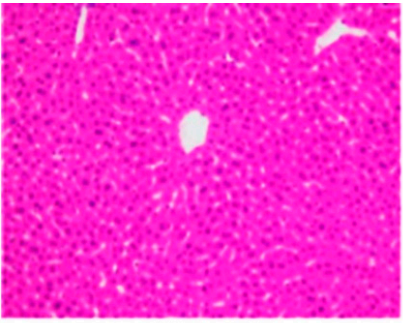

Normal

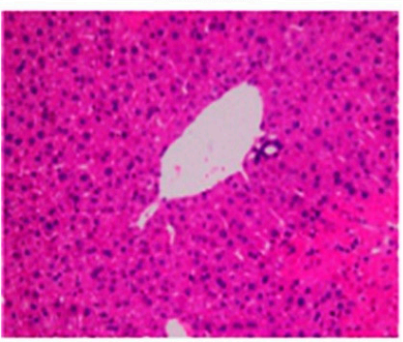

LSA-HN

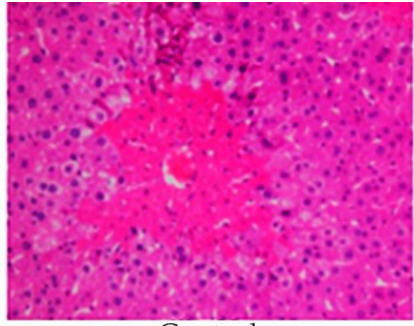

Control

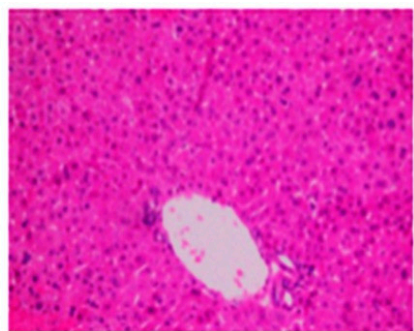

LSA-JX

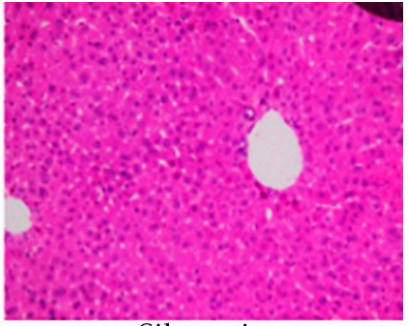

Silymarin

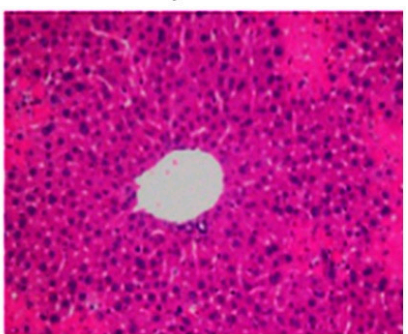

LSA-HB

Figure 1. H \& E pathological observation of liver in mice. Magnification $100 \times$. Silymarin, mice treated with $200 \mathrm{mg} / \mathrm{kg}$ silymarin; LSA-HN, mice treated with $400 \mathrm{mg} / \mathrm{kg}$ Lotus plumule alkaloids (Hunan, China); LSA-JX, mice treated with $400 \mathrm{mg} / \mathrm{kg}$ Lotus plumule alkaloids (Jiangxi, China); LSA-HB, mice treated with $400 \mathrm{mg} / \mathrm{kg}$ Lotus plumule alkaloids (Hubei, China).

\subsection{Expression of Inflammation-related Genes in Mouse Liver Tissues}

Figure 2 reveals that the hepatic mRNA expression of TNF- $\alpha$ and NF-KB was weakest, while the expression of IкB- $\alpha$ was strongest in the normal group. The expression of TNF- $\alpha$ and NF- $\mathrm{kB}$ increased significantly $(p<0.05)$, whereas the expression of IкB- $\alpha$ decreased significantly $(p<0.05)$ after induction of liver injury by $\mathrm{CCl}_{4}$. Silymarin and alkaloids from Lotus plumules could significantly 
$(p<0.05)$ inhibit the upregulated expression of TNF- $\alpha$ and NF- $\mathrm{kB}$, and downregulated expression of IкB- $\alpha$ in the injured liver tissues of mice.
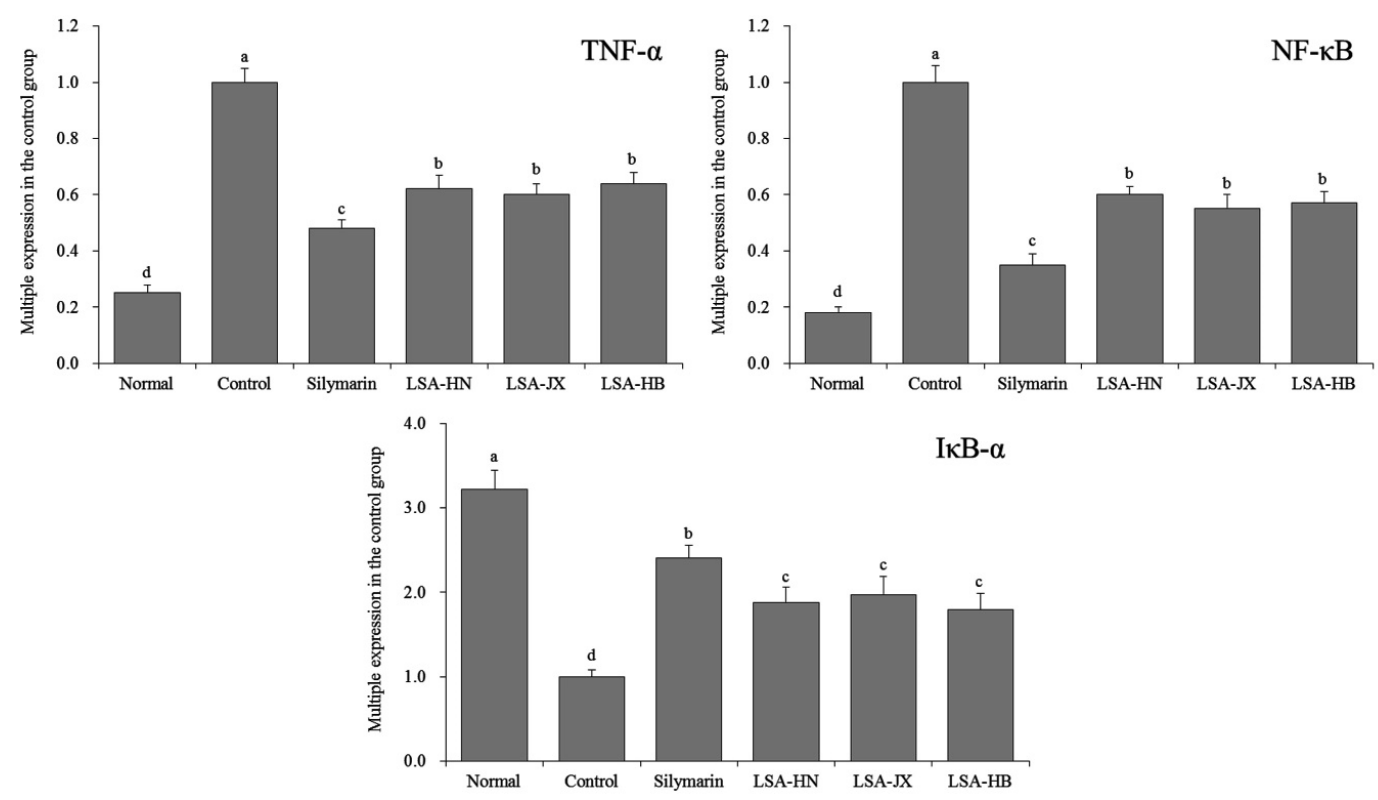

Figure 2. The TNF- $\alpha$, NF- $k B$ and I $\kappa B-\alpha$ mRNA expression in liver of mice. ${ }^{a-d}$ Mean values with different superscript letters are significantly different $(p<0.05)$ by the Duncan's multiple-range test. Silymarin, mice treated with $200 \mathrm{mg} / \mathrm{kg}$ silymarin; LSA-HN, mice treated with $400 \mathrm{mg} / \mathrm{kg}$ Lotus plumule alkaloids (Hunan, China); LSA-JX, mice treated with $400 \mathrm{mg} / \mathrm{kg}$ Lotus plumule alkaloids (Jiangxi, China); LSA-HB, mice treated with $400 \mathrm{mg} / \mathrm{kg}$ Lotus plumule alkaloids (Hubei, China).

\subsection{Expression of Oxidation-Related mRNA in Liver Tissues of Mice}

Figure 3 shows that the hepatic mRNA expression of $\mathrm{Cu} / \mathrm{Zn}-\mathrm{SOD}, \mathrm{Mn}-\mathrm{SOD}$, and CAT was strongest in the normal group, while that in the control group was weakest. Silymarin and alkaloids from Lotus plumules could significantly upregulate the mRNA expression of $\mathrm{Cu} / \mathrm{Zn}-\mathrm{SOD}, \mathrm{Mn}-\mathrm{SOD}$, and CAT in the injured liver tissues of mice.
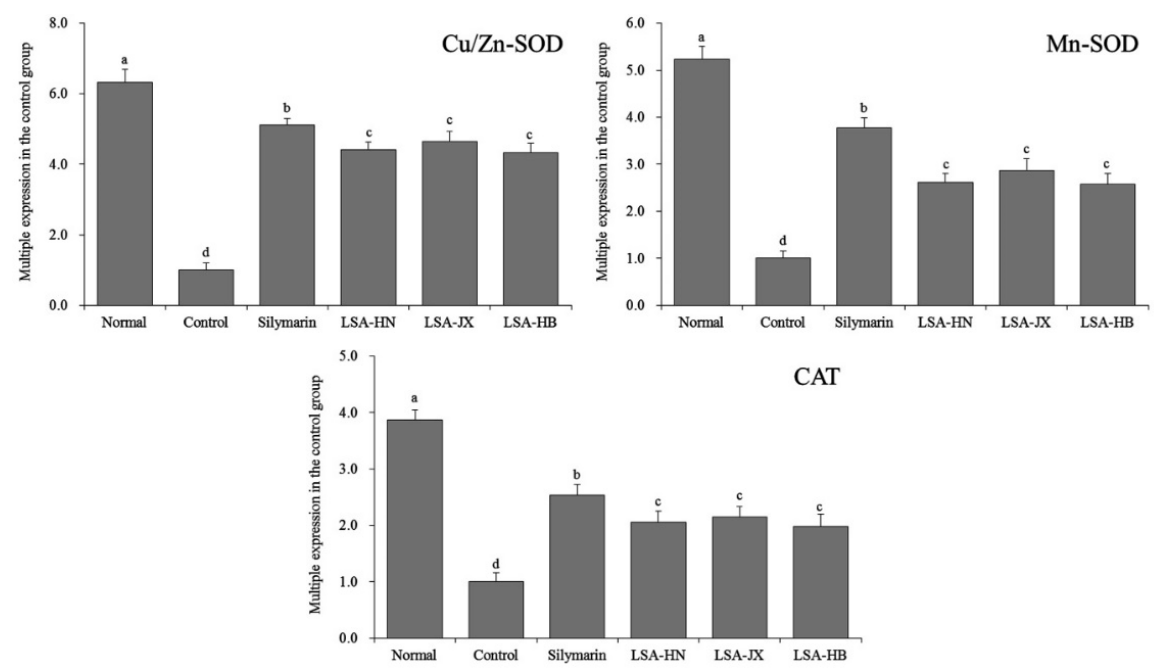

Figure 3. The $\mathrm{Cu} / \mathrm{Zn}-\mathrm{SOD}, \mathrm{Mn}-\mathrm{SOD}$ and CAT mRNA expression in liver of mice. ${ }^{\mathrm{a}-\mathrm{d}}$ Mean values with different superscript letters are significantly different $(p<0.05)$ by the Duncan's multiple-range test. Silymarin, mice treated with $200 \mathrm{mg} / \mathrm{kg}$ silymarin; LSA-HN, mice treated with $400 \mathrm{mg} / \mathrm{kg}$ Lotus plumule alkaloids (Hunan, China); LSA-JX, mice treated with $400 \mathrm{mg} / \mathrm{kg}$ Lotus plumule alkaloids (Jiangxi, China); LSA-HB, mice treated with $400 \mathrm{mg} / \mathrm{kg}$ Lotus plumule alkaloids (Hubei, China). 


\section{Discussion}

As one of the five internal organs, the liver plays a very important role. Hepatic injury may threaten the health of the body and is even lethal. At present, the degree of liver injury is clinically assessed with various indices, including the liver index, serum biochemical index, and liver tissue oxidation index. The liver index, also known as liver coefficient, is one of the pathological indicators of liver injury, which has been widely used to evaluate the degree of carbon tetrachloride-induced hepatic injury. The changes in liver weight can directly reflect the damage of liver [18]. The liver is a metabolic organ of mice. The decreased liver weight directly affects the metabolic capacity of animals. The liver is also one of the immune organs in animals [19]. Therefore, measurement of the liver index can directly reflect the structural changes and hepatic functions, and can be used to evaluate the degree of liver injury in mice [20]. Results of this study confirmed that $\mathrm{CCl}_{4}$ increased the organ index, and alkaloids from Lotus plumules could effectively alleviate increased liver index to a level very close to normal mice, which was comparable to silymarin, the common treatment drug for liver injury.

Hepatocytic membrane permeability increases after $\mathrm{CCl}_{4}$ induces liver injury, leading to inflammation of the liver. Transaminases are released from hepatic cells into the blood, and serum levels of ALT and AST increase [21]. The TBIL index reflects the process of the metabolic process of bile components, in which hepatocytes intake indirect bilirubin, combine it with $\mathrm{Y}$ and $\mathrm{Z}$ proteins, and transport it to the endoplasmic reticulum where indirect bilirubin binds to glucuronic acid to form bilirubin. Therefore, hepatocytes have the function of intaking, binding, and excreting bilirubin [22]. When $\mathrm{CCl}_{4}$ injures liver tissue, bilirubin flows back into the blood, leading to an increase in total bilirubin (TBIL) in the serum. Therefore, the change in serum TBIL content can be used to assess the degree of liver injury [23]. Increased levels of AST, ALT, and TBIL indicate exacerbated liver injury. The experimental data of this study also confirmed that $\mathrm{CCl}_{4}$ led to increased AST, ALT, and TBIL levels in mice. Alkaloids from Lotus plumules could significantly reduce the serum levels of AST, ALT, and TBIL in mice, and the effect was close to silymarin, a drug for liver diseases.

$\mathrm{CCl}_{4}$ causes oxidative stress and induces a large number of free radicals in the liver tissues of mice [24]. The activity of SOD can be used to evaluate the degree of liver injury. Regulation and promotion of SOD is the main mechanism of enzymatic antioxidant activity. Therefore, the level of SOD activity reflects the degree of hepatic cell injury [24]. MDA is the metabolic end product of oxidative injury and is accumulated in the body after liver injury. The level of MDA reflects the degree of oxidative damage. It is also a sensitive indicator of liver injury [25]. In this study, alkaloids from Lotus plumules could enhance SOD activity and reduce MDA level in the injured liver tissue of mice, thereby preventing $\mathrm{CCl}_{4}$-induced liver injury.

TNF- $\alpha$ is a polypeptide medium with extensive biological activities, which mediates liver injury caused by various factors. Liver injury is directly related to the increase of TNF- $\alpha$ [26]. NF- $\mathrm{kB}$ is a converging point of various signaling pathways, and plays a key role in various diseases, such as trauma and infection by regulating inflammatory response, and cellular apoptotic genes. There is a NF- $\mathrm{KB}$ binding site on the TNF- $\alpha$ promoter. Activated by traumatic stress, endotoxin, and other factors, NF- $\mathrm{KB}$ promotes the expression of apoptotic genes and TNF- $\alpha$. The increased TNF- $\alpha$ activates NF- $\mathrm{KB}$ again while mediating apoptosis, which promotes cellular apoptosis and cytokines, such as TNF- $\alpha$, resulting in a cascade of inflammatory responses centered on NF- $k B$ [27].

$\mathrm{I} \kappa \mathrm{B}-\alpha$ is an inhibitory protein of nuclear factor NF- $\mathrm{KB}$. It binds to NF- $\mathrm{KB}$ via an ankyrin repeat motif and covers the nuclear localization sequence (NLS) of its Rel homology domain, which inhibits the activity of NF- $\mathrm{kB}$ [28]. In the resting state, two subunits of NF- $\mathrm{KB}$ p65, p50 and IкB- $\alpha$, exist in the cytoplasm in an inactivated state. When the upstream signal activates IKK (IkB kinase), the activated IKK can ubiquitinate, phosphorylate, and degrade I $\kappa B-\alpha$, which activates the two subunits of NF- $\kappa B$ from the inactivated state and transfers them from the cytoplasm into the nucleus. The two subunits bind to the corresponding inflammation-related genes, initiate the transcription of inflammatory cytokines, and induce inflammation [29]. Therefore, alkaloids from Lotus plumules can prevent liver 
injury by inhibiting the expression of TNF- $\alpha, N F-\kappa B$, and promoting the expression of IкB- $\alpha$ in liver tissues.

SOD can be divided into three types according to the different metal prosthetic groups it contains. The first one is $\mathrm{Cu} / \mathrm{Zn}-\mathrm{SOD}$ containing metal prosthetic groups of $\mathrm{Cu}$ and $\mathrm{Zn}$, which is the most common enzyme and mainly exists in the cytoplasm. The second one is Mn-SOD containing the metal prosthetic group $\mathrm{Mn}$, which exists in the mitochondria of eukaryotic cells and prokaryotic cells. Both $\mathrm{Cu} / \mathrm{Zn}-\mathrm{SOD}$ and $\mathrm{Mn}-\mathrm{SOD}$ are important antioxidant enzymes that scavenge free radicals in living organisms. They can resist and block the damage caused by oxygen free radicals, promptly repair damaged cells, and reverse cellular injury caused by $\mathrm{CCl}_{4}$-induced free radicals [30]. CAT, mainly distributed in the peroxide of cells, can degrade $\mathrm{H}_{2} \mathrm{O}_{2}$ into water and oxygen and clear $\mathrm{H}_{2} \mathrm{O}_{2}$ through a series of metabolic reactions to alleviate tissue inflammation and injury caused by oxidative stress [31]. Alkaloids from Lotus plumules show promising efficacy in alleviating liver injury by increasing the levels of antioxidant enzymes ( $\mathrm{Cu} / \mathrm{Zn}-\mathrm{SOD}, \mathrm{Mn}-\mathrm{SOD}$, and CAT), which is comparable to the efficacy of the drug silymarin.

There are many studies to prove that Lotus plumules alkaloids contain only three components, namely, liensinine, isoliensinine and neferine [32-34]. Liensinine can inhibit lipid peroxidation in experimental animals [35], and study has confirmed that it has an antioxidant effect [36], thus exerting its influence on inflammation. Isoliensinine also has a good antioxidant effect in vitro [37], and has a significant inhibitory effect on lipid peroxidation in liver tissue [38]. Neferine has a good recovery effect on tissue damage caused by oxygen free radicals, and can also condition the body's low density lipoprotein and very low density lipoprotein [39]. Liensinine, isoliensinine and neferine have good antioxidant and lipid peroxidation inhibition abilities, which can resist irreversible oxidative stress damage of liver tissue caused by carbon tetrachloride, thus playing a protective role in liver tissue.

\section{Conclusions}

This study showed that the alkaloids from Lotus plumules collected from different regions could prevent $\mathrm{CCl}_{4}$-induced liver injury by regulating the levels of oxidative stress and inflammation in mice. The experimental results confirmed that alkaloids of Lotus plumules from different regions could downregulate serum AST, ALT, and TBIL, enhance SOD activity, and reduce MDA levels in the injured liver tissues of mice. Pathological observations also confirmed that alkaloids from Lotus plumules could control the injuries of hepatocytes induced by $\mathrm{CCl}_{4}$. Further qPCR experiments also demonstrated that alkaloids from Lotus plumules could upregulate the expression of IкB- $\alpha, \mathrm{Cu} / \mathrm{Zn}-\mathrm{SOD}, \mathrm{Mn}-\mathrm{SOD}$, and CAT mRNA and downregulate the expression of TNF- $\alpha$ and NF- $\mathrm{kB}$ in injured liver tissues of mice. By regulating the above factors, these alkaloids could alleviate liver damage caused by $\mathrm{CCl}_{4}$, and the effect was close to the hepatic treatment drug silymarin. Therefore, it can be proved that alkaloids of Lotus plumules from food are bioactive substances with good hepatic protective function, as well as promising application value. This study has provided a theoretical basis for further human experiments, and the specific mechanism of its role needs further research.

Author Contributions: B.L. and J.L. performed the majority of the experiments and wrote the manuscript; R.Y., J.M. and X.Z. contributed to the data analysis; X.Z. designed and supervised the study and checked the final manuscript.

Funding: The present research was supported by the Program for Innovation Team Building at Institutions of Higher Education in Chongqing (CXTDX201601040), China.

Conflicts of Interest: The authors declare no conflict of interest.

\section{References}

1. Xiong, W.; Chen, X.; Lv, G.; Hu, D.; Zhao, J.; Li, S. Optimization of microwave-assisted extraction of bioactive alkaloids from lotus plumule using response surface methodology. J. Pharm. Anal. Technol. 2016, 6, 382-388. [CrossRef] [PubMed] 
2. Zhou, M.; Jiang, M.; Ying, X.; Cui, Q.; Han, Y.; Hou, Y.; Gao, J.; Bai, G.; Luo, G. Identification and comparison of anti-inflammatory ingredients from different organs of Lotus Nelumbo by UPLC/Q-TOF and PCA coupled with a NF-kB reporter gene assay. PLoS One 2013, 8, e81971. [CrossRef] [PubMed]

3. Zhu, M.; Liu, T.; Guo, M. Current advances in the metabolomics study on lotus seeds. Front Plant Sci. 2016, 7, 891. [CrossRef] [PubMed]

4. Lv, S.; Pan, Y.; Tao, R.; Zhang, X. The reverse effects of liensinine and lotusin on leftventricular hypertrophy of renovascular hypertensive rats. J. Nanjing Univ. Tradit. Chinese Med. (Nat. Sci.) 2008, 24, 327-329.

5. Yi, R.; Feng, X.; Li, G.; Peng, D.; Mu, J.; Fu, C.; Zhao, X. Alkaloids from Ba lotus seeds (Nelumbo nucifera gaertn) attenuates $\mathrm{HCl} /$ ethanol induced gastric mucosal injury in icr mice. Food Sci. 2017, 38, 221-231.

6. Stawicki, S.P.A. Trends in nonoperative management of traumatic injuries -A synopsis. Int. J. Crit. Illn. Inj. Sci. 2017, 7, 38-57. [CrossRef] [PubMed]

7. Mardones, M.; Valenzuela, R.; Romanque, P.; Covarrubias, N.; Anghileri, F.; Fernández, V.; Videla, L.A.; Tapia, G. Prevention of liver ischemia reperfusion injury by a combined thyroid hormone and fish oil protocol. J. Nutr. Biochem. 2012, 23, 1113-1120. [CrossRef]

8. Williams, V.; Brichler, S.; Khan, E.; Chami, M.; Dény, P.; Kremsdorf, D.; Gordien, E. Large hepatitis delta antigen activates STAT-3 and NF-кB via oxidative stress. J. Viral. Hepat. 2012, 19, 744-753. [CrossRef]

9. DiSilvestro, R.A.; Carlson, G.P. Inflammation, an inducer of metallothionein, inhibits carbon-tetrachlorideinduced hepatotoxicity in rats. Toxicol. Lett. 1992, 60, 175-181. [CrossRef]

10. Jung, H.A.; Min, B.S.; Yokozawa, T.; Lee, J.H.; Kim, Y.S.; Choi, J.S. Anti-Alzheimer and antioxidant activities of Coptidis Rhizoma alkaloids. Biol. Pharm. Bull. 2009, 32, 1433-1438. [CrossRef]

11. Zhu, H.; Wen, L.; Geng, Y.L.; Wang, X.; Jia, W.T.; Wang, D.J.; Yan, Y.H. Antioxidant activity of alkaloids in Caulis Mahoniae. Shandong Sci. 2016, 29, 24-28.

12. Guo, X.; Yang, S.J.; Cao, X. Effects of total alkaloid of clivia miniata on the hepatorenal function and antioxidant ability in rats. China Pract. Med. 2009, 4, 36-37.

13. Li, N.; Song, J.C. Research advance in anti-tumor activity of alkaloids from Nelumbo nuciferia gaertn. China Pharm. 2016, 19, 2141-2143.

14. Feng, X.; Yi, R.K.; Sun, P.; Peng, D.G.; Zhao, X. In vitro anticancer activity of alkaloids extracted from Ba lotus seeds against human hepatoma HepG2 cells. Food Sci. 2017, 38, 206-211.

15. Yang, X.Q.; Song, J.C.; Xie, S.L.; Hao, H.H. Comparison of antioxidant activity of the total alkaloids in lotus plumule by different extraction methods. China Med. Herald 2015, 12, 100-104.

16. Wang, R.; Feng, X.; Zhu, K.; Zhao, X.; Suo, H. Preventive activity of banana peel polyphenols on $\mathrm{CCl}_{4}$-induced experimental hepatic injury in Kunming mice. Exp. Ther. Med. 2016, 11, 1947-1954. [CrossRef] [PubMed]

17. Qian, Y.; Zhang, J.; Zhou, X.; Yi, R.; Mu, J.; Long, X.; Pan, Y.; Zhao, X.; Liu, W. Lactobacillus plantarum CQPC11 isolated from sichuan pickled cabbages antagonizes D-galactose-induced oxidation and aging in mice. Molecules 2018, 23, 3026. [CrossRef]

18. Wang, L.; Cheng, D.; Wang, H.; Di, L.; Zhou, X.; Xu, T.; Yang, X.; Liu, Y. The hepatoprotective and antifibrotic effects of Saururus chinensis against carbon tetrachloride induced hepatic fibrosis in rats. J. Ethnopharmacol. 2009, 126, 487-491. [CrossRef]

19. Pan, Y.; Long, X.; Yi, R.; Zhao, X. Polyphenols in Liubao tea can prevent $\mathrm{CCl}_{4}$-Induced hepatic damage in mice through its antioxidant capacities. Nutrients 2018, 10, 1280. [CrossRef]

20. Chen, X.; Zhang, J.; Yi, R.; Mu, J.; Zhao, X.; Yang, Z. Hepatoprotective effects of Lactobacillus on carbon tetrachloride-induced acute liver injury in mice. Int. J. Mol. Sci. 2018, 19, 2212. [CrossRef]

21. Go, J.; Kim, J.E.; Koh, E.K.; Song, S.H.; Sung, J.E.; Lee, H.A.; Lee, Y.H.; Lim, Y.; Hong, J.T.; Hwang, D.Y. Protective effect of gallotannin-enriched extract isolated from galla rhois against $\mathrm{CCl}_{4}$-Induced hepatotoxicity in ICR mice. Nutrients 2016, 8, 107. [CrossRef] [PubMed]

22. Chen, M.; Wang, T.; Jiang, Z.Z.; Shan, C.; Wang, H.; Wu, M.J.; Zhang, S.; Zhang, Y.; Zhang, L.Y. Anti-inflammatory and hepatoprotective effects of total flavonoid C-glycosides from Abrus mollis extracts. Chin. J. Nat. Med. 2014, 12, 590-598. [CrossRef]

23. Gao, Y.; Liu, W.; Wang, W.; Zhao, X.; Wang, F. Polyguluronate sulfate (PGS) attenuates immunological liver injury in vitro and in vivo. Int. J. Biol. Macromol. 2018, 114, 592-598. [CrossRef] [PubMed]

24. Sipes, I.G.; el Sisi, A.E.; Sim, W.W.; Mobley, S.A.; Earnest, D.L. Reactive oxygen species in the progression of $\mathrm{CCl}_{4}$-induced liver injury. Adv. Exp. Med. Biol. 1991, 283, 489-497. [PubMed] 
25. Mihas, A.A.; Kanji, V.K.; Mihas, T.A.; Joseph, R.M.; Markov, A.K.; Heuman, D.M. Fructose diphosphate attenuates the acetaminophen-induced liver injury in the rat evidence for involvement of nitric oxide. Res. Commun. Mol. Pathol. Pharmacol. 2003, 113-114, 253-266.

26. Schwabe, R.F.; Brenner, D.A. Mechanisms of liver injury. I. TNF-alpha-induced liver injury: role of IKK, JNK, and ROS pathways. Am. J. Physiol. Gastrointest. Liver Physiol. 2006, 290, 583-589. [CrossRef] [PubMed]

27. Elnahas, E.M.; Zeid, M.S.; Kawy, H.S.; Hendawy, N.; Baher, W. Celecoxib attenuates depressive-like behavior associated with immunological liver injury in C57BL/6 mice through TNF- $\alpha$ and NF-kb dependent mechanisms. Life Sci. 2016, 163, 23-37. [CrossRef]

28. Duckworth, E.A.; Butler, T.; Collier, L.; Collier, S.; Pennypacker, K.R. NF-kappaB protects neurons from ischemic injury after middle cerebral artery occlusion in mice. Brain Res. 2006, 1088, 167-175. [CrossRef]

29. Peng, Z.; Gong, X.; Yang, Y.; Huang, L.; Zhang, Q.; Zhang, P.; Wan, R.; Zhang, B. Hepatoprotective effect of quercetin against LPS/d-GalN induced acute liver injury in mice by inhibiting the IKK/NF-KB and MAPK signal pathways. Int. Immunopharmacol. 2017, 52, 281-289. [CrossRef]

30. Zhong, Z.; Froh, M.; Wheeler, M.D.; Smutney, O.; Lehmann, T.G.; Thurman, R.G. Viral gene delivery of superoxide dismutase attenuates experimental cholestasis-induced liver fibrosis in the rat. Gene Ther. 2002, 9, 183-191. [CrossRef]

31. Deng, X.; Wu, K.; Wan, J.; Li, L.; Jiang, R.; Jia, M.; Jing, Y.; Zhang, L. Aminotriazole attenuated carbon tetrachloride-induced oxidative liver injury in mice. Food Chem. Toxicol. 2012, 50, 3073-3078. [CrossRef] [PubMed]

32. Wang, X.Y.; Lian, Y.F.; Chu, K.D.; Xu, W.; Li, R. Determination of alkaloids in Nelumbinis plumula from Fujian province by HPLC. Chinese J. Exp. Tradit. Med. Formulae 2012, 18, 117-120.

33. Zhao, L.B.; Jin, Y.; Wang, J.L. Determination of three alkaloids in total alkaloids exfracts from Lotus plumule by RP-HPLC. China J. Chinese Mater. Med. 2007, 32, 1768-1770.

34. Tu, X.; Shang, J.; Xue, Y.; Pan, Y. Comparison of three phenolic alkaloids' content in Plumula Nelumbini by using two HPLC detectors. J. Nanjing Univ. Tradit. Chinese Med. 2011, 27, 69-72.

35. Wang, H.; Liu, G.; Yang, L.; Luo, S.D. Effects of liensinine on blood lipids and lipid peroxidation in experimental hyperlipidemia rats. Nat. Prod. Res. Deve. 2015, 17, 722-725.

36. Wang, H.; Zhou, L.; Liu, G. Protective effect of Liensinine on oxidative damage of erythrocyte ghost by oxygen free radicals. Chinese Pharm. Bull. 2006, 22, 1088-1091.

37. Wang, H.; Sun, C.Y.; Liu, G. Antioxidative effect of isoliensinine in vitro. Chinese J. Biochem. Pharm. 2005, 26, 21-23.

38. Wang, H.; Yang, L.; Yang, J.; Luo, S.D. Effect of isoliensinine on lipid peroxidation in rat liver hemogenate. Chinese J. Hosp. Pharm. 2005, 25, 402-404.

39. Tang, X.Q.; Cao, J.G. Review on the pharmacological research of neferine. Chinese Pharm. Bull. 2004, 20, 8-10. 